\title{
Long-term outcomes of percutaneous mitral balloon valvuloplasty versus open cardiac surgery
}

\author{
Jae-Kwan Song, MD, ${ }^{a}$ Mi-Jeong Kim, MD, ${ }^{\text {a }}$ Sung-Cheol Yun, $\mathrm{PhD},{ }^{\mathrm{b}}$ Suk Jung Choo, MD, ${ }^{\mathrm{c}}$ \\ Jong-Min Song, MD, ${ }^{a}$ Hyun Song, MD, ${ }^{c}$ Duk-Hyun Kang, MD, ${ }^{a}$ Cheol Hyun Chung, MD, ${ }^{c}$ \\ Duk Woo Park, MD, ${ }^{\text {a }}$ Seung Whan Lee, MD, ${ }^{\mathrm{a}}$ Young-Hak Kim, MD, ${ }^{\mathrm{a}}$ Cheol Whan Lee, MD, ${ }^{\mathrm{a}}$

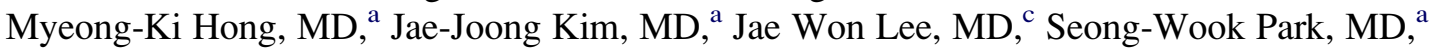 \\ and Seung-Jung Park, MD
}

Objectives: We sought to compare long-term outcomes between percutaneous mitral valvuloplasty and open heart surgery.

\begin{abstract}
Methods: The study evaluated 402 patients who underwent percutaneous mitral valvuloplasty and 159 patients who underwent open heart surgery between January 1, 1995, and December 31, 2000. The rates of cardiovascular death or repeated intervention (redo percutaneous mitral valvuloplasty or open heart surgery) were determined over a median follow-up of 109 months (mean \pm SD, $106 \pm 27$ ). The therapeutic effects on adverse outcomes were estimated by the Cox proportional hazards model adjusting differences in the severity of illness before intervention. The effects of the cardiac rhythm and echocardiographic score were also tested.
\end{abstract}

Results: The observed (unadjusted) event-free survival was similar for both groups, and the hazard ratio for the
clinical events after percutaneous mitral valvuloplasty as compared with after open heart surgery was $1.510(95 \%$
confidence interval, $0.914-2.496 ; P=.1079)$. However, the adjusted hazard ratio was $3.729(95 \%$ confidence
interval, $1.963-7.082 ; P<.0001)$, showing a higher event-free survival in the open heart surgery group. The
adjusted hazard ratio after percutaneous mitral valvuloplasty as compared with after open heart surgery in patients
with echocardiographic scores of 8 or more and atrial fibrillation were $5.348(95 \%$ confidence interval, $2.504-$
$11.422 ; P<.001)$ and $3.440(95 \%$ confidence interval, $1.805-6.555 ; P=.0002)$, respectively, whereas the haz-
ard ratio in patients with echocardiographic scores less than 8 and normal sinus rhythm did not show differences.

Conclusions: Open heart surgery was associated with a higher adjusted rate of long-term event-free survival than percutaneous mitral valvuloplasty. Patients with high echocardiographic scores or atrial fibrillation showed better outcomes after open heart surgery. (J Thorac Cardiovasc Surg 2010;139:103-10)

Percutaneous mitral valvuloplasty (PMV) has been developed as a logical extension of surgical closed commissurotomy for mitral stenosis (MS), ${ }^{1}$ and excellent hemodynamic improvement with favorable outcome has been reported by many investigators. ${ }^{2-11}$ PMV has rapidly become the initial treatment of choice for selected patients with MS owing to benefits such as low early morbidity. As a consequence, open heart surgery (OHS) including open mitral commissurotomy (OMC) and mitral valve replacement (MVR) is now largely reserved for a minority of patients with a calcified mitral valve or left atrial thrombi. However, most clinical studies report that the mean follow-up duration associated with excellent clinical outcomes after PMV is less than 5 years. ${ }^{6-11}$ In addition, cumulative clinical expe-

\footnotetext{
From the Divisions of Cardiology, ${ }^{\mathrm{a}}$ Biostatics, ${ }^{\mathrm{b}}$ Cardiac Surgery, ${ }^{\mathrm{c}}$ Asan Medical Center, University of Ulsan College of Medicine, Seoul, South Korea.

Received for publication Jan 30, 2009; revisions received April 3, 2009; accepted for publication April 23, 2009; available ahead of print July 6, 2009.

Address for reprints: Jae-Kwan Song, MD, Cardiology, Asan Medical Center, University of Ulsan College of Medicine, 388-1 Poongnap-dong Songpa-ku, Seoul 138-

736, South Korea (E-mail: jksong@amc.seoul.kr).

$0022-5223 / \$ 36.00$

Copyright (C) 2010 by The American Association for Thoracic Surgery

doi:10.1016/j.jtcvs.2009.04.022
}

rience shows that gradual and progressive occurrence of restenosis with late functional deterioration occurring 5 years after PMV could be a potentially important clinical issue, ${ }^{7}$ especially when discussing indications for PMV. Furthermore, bileaflet MVR has long been the definitive aggressive treatment option for patients with MS and shows greater durability than OMC. ${ }^{12-14}$ Thus, the efficacy and long-term outcomes after PMV and OHS need to be reassessed. The present study used observational data to compare long-term outcomes in patients with MS who underwent PMV or OHS.

\section{METHODS \\ Subjects}

The study involved patients who underwent PMV or OHS in our institution owing to hemodynamically significant MS between January 1, 1995, and December 31, 2000. Exclusion criteria included prior PMV or OHS concomitant significant mitral regurgitation, or aortic valvular or coronary lesions that required additional aortic valve procedures or coronary artery bypass grafting. The study group comprised 402 patients who underwent PMV and 159 patients who underwent OHS. The definite treatment strategy for patients with MS, PMV or OHS, was determined at the discretion of the attending cardiologists or referral physicians and was based on echocardiographic score, patient age, and comorbidities, including left atrial thrombi. 


\author{
Abbreviations and Acronyms \\ $\mathrm{CI}=$ confidence intervals \\ HR = hazard ratio \\ MS $=$ mitral stenosis \\ $\mathrm{MVR}=$ mitral valve replacement \\ OHS $=$ open heart surgery \\ $\mathrm{OMC}=$ open mitral commissurotomy \\ PMV $=$ percutaneous mitral valvuloplasty
}

Our institutional review board approved the retrospective analysis of the clinical data of these subjects.

\section{PMV}

Cardiac catheterization confirmed severe MS without significant mitral regurgitation. Experienced physicians then performed PMV using the Inoue balloon technique while monitoring the conventional hemodynamic parameters.

\section{OHS}

Conventional normothermic cardiopulmonary bypass was performed with bicaval and ascending aortic cannulation. Myocardial protection was achieved with antegrade and retrograde tepid blood cardioplegia. MVR or OMC was performed at the surgeons' discretion, largely on the basis of the morphologic features of the rheumatic involvement of the mitral apparatus. OMC was performed by opening the fused commissures using sharp and blunt dissection to create a wide mitral valve orifice. MVR was performed using the interrupted suture technique with St Jude Medical (St Jude Medical, Inc, St Paul, Minn) (101 patients) and Mira (19 patients), Tekna (10 patients), or Carpentier-Edwards (10 patients) prostheses (all Edwards Lifesciences, Irvine, Calif). Some patients also underwent tricuspid valve repair with or without the maze procedure.

\section{Echocardiographic Evaluation}

Comprehensive 2-dimensional and color Doppler echocardiographic evaluation was performed in all patients before PMV or OHS with a Hewlett-Packard Sonos 2500 or 5500 imaging system (Hewlett-Packard Company, Palo Alto, Calif) equipped with a $2.5-\mathrm{MHz}$ transducer. Besides routine measurements of cardiac chamber dimensions and ejection fraction by the modified Simpson method, the mitral gradient and the peak pressure gradient of tricuspid regurgitation were calculated. The morphologic features of the mitral valve were categorized as previously described, and the total echocardiographic score was obtained by adding the scores of each of the following individual morphologic features: leaflet mobility, thickness, calcification, and subvalvular lesions. ${ }^{15}$ The mitral valve area was measured by direct planimetry at the parasternal short-axis view, and the continuous wave Doppler technique was used to calculate the mitral gradient and the peak pressure gradient of tricuspid regurgitation. Mitral and tricuspid regurgitation were graded from 0 to $4+$, depending on the spatial extent of the color flow jet area expressed as a percentage of the left or right atrial area.

\section{Follow-up}

Clinical follow-up was performed 2 and 6 months after PMV or OHS and yearly thereafter until December 2006. Clinical data were collected either during patient visits to the outpatient clinic or by telephone interviews. The primary end points were defined as the clinical events of cardiovascular death and redo PMV or OHS. The National Vital Statistics death file was used to confirm mortality during follow-up.
TABLE 1. Baseline clinical and echocardiographic characteristics

\begin{tabular}{|c|c|c|c|}
\hline & OHS $(n=159)$ & $\operatorname{PMV}(n=402)$ & $P$ value \\
\hline Age, y & $52 \pm 9$ & $44 \pm 11$ & $<.001$ \\
\hline Female, n $(\%)$ & $93(59)$ & $301(75)$ & $<.001$ \\
\hline Atrial fibrillation, n (\%) & $134(84)$ & $146(36)$ & $<.001$ \\
\hline $\begin{array}{l}\text { Left atrial AP } \\
\text { diameter, } \mathrm{mm}\end{array}$ & $60 \pm 10$ & $53 \pm 7$ & $<.001$ \\
\hline $\begin{array}{l}\text { LV systolic } \\
\quad \text { dimension, mm }\end{array}$ & $36 \pm 6$ & $33 \pm 6$ & $<.001$ \\
\hline $\begin{array}{l}\text { LV diastolic } \\
\text { dimension, } \mathrm{mm}\end{array}$ & $51 \pm 6$ & $49 \pm 6$ & .040 \\
\hline $\begin{array}{l}\text { LV ejection } \\
\quad \text { fraction, } \%\end{array}$ & $55 \pm 9$ & $59 \pm 7$ & $<.001$ \\
\hline $\begin{array}{l}\text { Mitral valve } \\
\text { area, } \mathrm{cm}^{2}\end{array}$ & $0.86 \pm 0.26$ & $0.95 \pm 0.21$ & $<.001$ \\
\hline $\begin{array}{l}\text { Mean mitral } \\
\quad \text { gradient, } \mathrm{mm} \mathrm{Hg}\end{array}$ & $13 \pm 6$ & $13 \pm 6$ & .667 \\
\hline MR grade & $0.8 \pm 0.8$ & $0.6 \pm 0.6$ & .001 \\
\hline TR grade & $1.7 \pm 1.1$ & $1.4 \pm 0.9$ & .001 \\
\hline $\begin{array}{r}\text { Peak velocity } \\
\text { of TR, m/s }\end{array}$ & $3.1 \pm 0.7$ & $2.9 \pm 0.6$ & .013 \\
\hline \multicolumn{4}{|l|}{ Echocardiographic score } \\
\hline Leaflet mobility & $2.1 \pm 0.5$ & $1.6 \pm 0.5$ & $<.001$ \\
\hline Leaflet thickening & $2.5 \pm 0.6$ & $2.1 \pm 0.5$ & $<.001$ \\
\hline Subvalvular scarring & $2.4 \pm 0.6$ & $2.0 \pm 0.5$ & $<.001$ \\
\hline Calcification & $2.6 \pm 0.6$ & $1.7 \pm 0.7$ & $<.001$ \\
\hline Total & $9.6 \pm 1.9$ & $7.3 \pm 1.4$ & $<.001$ \\
\hline
\end{tabular}

$A P$, Anteroposterior; $L V$, left ventricular; $M R$, mitral regurgitation; $T R$, tricuspid regurgitation. Continuous variables are expressed as mean $\pm \mathrm{SD}$.

A nationwide survey was done to confirm redo PMV or OHS using cardiac surgery and percutaneous intervention reporting system. If a patient in the PMV group underwent OHS during follow-up, the patient was censored at the time of reoperation. Median follow-up duration was 109 months (mean $\pm \mathrm{SD}, 106 \pm 27$ ).

\section{Data Analysis}

Categorical variables are presented as numbers and percentages and were compared by $\chi^{2}$ or Fisher's exact test. Continuous variables are presented as mean $\pm \mathrm{SD}$ and were compared by the unpaired Student $t$ tests.

The Cox proportional hazards model was used to determine whether the long-term event-free survival differed significantly between PMV and OHS patients after controlling for the differences in preprocedural risk profiles. Also, Cox proportional hazards regression was used to determine whether there were treatment-related differences in the long-term event-free survival among patients with high total echocardiographic scores $(\geq 8)$ and those with atrial fibrillation. Multivariable analyses (Cox proportional hazards regression) involved a backward elimination technique, and only variables with a $P$ value of less than .10 were used in the final model. The proportional hazards assumption was confirmed through examination of $\log (-\log$ [survival]) curves and testing of partial (Schoenfeld) residuals, ${ }^{16}$ and no relevant violations were found.

Additionally, a propensity score analysis was carried out to determine the causal effect of the group on the long-term event-free survival. The propensity scores were estimated by multiple logistic regression analysis without regard to outcome variables. A full nonparsimonious model was developed including all variables presented in Table 1 . This model yielded a c-statistic of 0.911 , and a Hosmer-Lemeshow goodness-of-fit test $P$ value of .2338 indicating a strong ability to differentiate between patients undergoing PMV and those undergoing OHS. The individual propensity score was incorporated into Cox proportional hazards models as a covariate to calculate the 
propensity-adjusted hazard ratios (HRs). In addition, the propensity score was subdivided into quintiles. Usually, propensity score matching is mostly preferred in the aspect of reducing bias and mean squared error. However, it is necessary that the two treatment groups overlap well enough in terms of the propensity scores for sound analysis. However, in our study, the two treatment groups do not overlap well enough in terms of the propensity scores. Thus, we chose alternative methods (stratification and regression adjustment) for final analysis. Treatment effects were separately estimated within each quintile and then quintile estimates were combined to measure an overall estimate of the treatment effect using a stratified Cox regression model. All analyses were conducted with SAS software (version 8.2; SAS Institute, Inc, Cary, NC).

\section{RESULTS}

\section{Baseline Characteristics and Immediate Outcomes}

The study involved a total of 561 patients, comprising 402 PMV patients and 159 OHS patients. Of the OHS patients, $19(12 \%)$ underwent OMC and the remaining 140 underwent MVR. Concomitant tricuspid valve repair and maze procedures were performed in $38(24 \%)$ and $26(16 \%)$ OHS patients, respectively. Baseline clinical and echocardiographic characteristics for all patients are summarized in Table 1. OHS patient characteristics included a higher mean age, a prevalence of male sex, atrial fibrillation with a larger left atrium, lower left ventricular ejection fraction, smaller mitral valve area, and higher pulmonary artery pressure and echocardiographic scores. In the PMV group, 1 patient underwent emergency MVR immediately after PMV owing to the development of severe mitral regurgitation, but subsequently died. The surgical mortality was $2 \%$ (3/ 159 ) in the OHS group.

\section{Follow-up Data}

The median follow-up was 97 months in the OHS group and 112 months in the PMV group. The echocardiographic data at last follow-up showed lower mean mitral gradient $(4.1 \pm 2.1$ vs $6.8 \pm 3.5 \mathrm{~mm} \mathrm{Hg} ; P<.001)$ and peak pulmonary artery pressure $(25 \pm 2$ vs $30 \pm 3 \mathrm{~mm} \mathrm{Hg})$ in the OHS group. A total of $52(9 \%)$ patients died during follow-up (Table 2). The completeness of follow-up was $93 \%$, and higher mortality in the OHS group $(16 \%$ vs $7 \% ; P=$ .001 ) with significantly higher mean age could explain the observed difference of the median follow-up between the groups. Cardiovascular death comprised greater than two thirds of total deaths in both the PMV (18/27) and OHS $(17 / 25)$ groups. In the OHS group, 1 patient had prosthesis thrombosis and underwent emergency redo OHS, but subsequently died. Another patient underwent a redo MVR owing to infective endocarditis. In 2 patients, redo OHS for tricuspid valve replacement was required to control severe tricuspid regurgitation 64 and 72 months after initial MVR, respectively. In the PMV group, 51 patients underwent subsequent OHS and 10 patients redo PMV.

The observed unadjusted 5-year cardiovascular deathfree survival was 0.950 (95\% confidence interval [CI],
TABLE 2. Summary of clinical events

\begin{tabular}{lcc}
\hline & OHS $(\mathbf{n}=\mathbf{1 5 9})$ & PMV $(\mathbf{n}=\mathbf{4 0 2})$ \\
\hline Cardiovascular death, ${ }^{*} \mathrm{n}(\%)$ & $17(11 \%)$ & $18(5 \%)$ \\
$\quad$ Congestive heart failure, $\mathrm{n}$ & 3 & 6 \\
Cerebrovascular accident, $\mathrm{n}$ & 1 & 5 \\
Sudden death, $\mathrm{n}$ & 4 & 1 \\
Operative mortality, $\mathrm{n}$ (initial/redo) & $4(3 / 1)$ & $2(1 / 1)$ \\
Acute myocardial infarction, $\mathrm{n}$ & 1 & 1 \\
$\quad$ Subacute bacterial endocarditis, $\mathrm{n}$ & 4 & 3 \\
Noncardiovascular death & & \\
Malignancy, $\mathrm{n}$ & 5 & 5 \\
Accident/trauma, $\mathrm{n}$ & 1 & 2 \\
Suicide, $\mathrm{n}$ & 1 & 0 \\
Liver disease, $\mathrm{n}$ & 1 & 1 \\
Chronic renal failure, $\mathrm{n}$ & 0 & 1 \\
Repeated Intervention, $\dagger \mathrm{n}(\%)$ & $4(3 \%)$ & $61(15 \%)$ \\
OHS, $\mathrm{n}$ & 4 & 51 \\
Redo PMV, $\mathrm{n}$ & 0 & 10 \\
\hline$O H S$, Open heart surgery; $P M V$, percutaneous mitral valvuloplasty. $* P=.009 ;$ \\
$\dagger P<.001$.
\end{tabular}

$0.917-0.983)$ in the OHS group and $0.978(95 \% \mathrm{CI}$, 0.964-0.992) in the PMV group. The HR after PMV as compared with after OHS was 0.367 (95\% CI, 0.188-0.711; $P=$ $.003)$. However, after adjusting for age, gender, left atrial anteroposterior diameter, and echocardiographic score, the HR was $1.328(95 \% \mathrm{CI}, 0.542-3.257 ; P=.5352)$. Both unadjusted and adjusted cardiovascular death-free survival curves are presented in Figure 1 (adjusted Cox model for propensity score). For the unadjusted Kaplan-Meier survival curve, the survival was significantly higher after PMV than after OHS $(P=.0002)$, whereas there was no significant difference after adjustment $(P=.6887)$. The adjusted probability of cardiovascular death-free survival in the OHS groups was $98 \% \pm 1 \%$ at 5 years, $97 \% \pm 1 \%$ at 7 years, and $96 \% \pm 2 \%$ at 9 years; in the PMV group it was $98 \% \pm 1 \%$ at 5 years, $96 \% \pm 1 \%$ at 7 years, and $95 \% \pm 2 \%$ at 9 years.

The primary end point of the present study was the frequency of hard clinical events including cardiovascular death, redo PMV, and OHS. This frequency was found to be $13 \%(20 / 159)$ in the OHS group and $19 \%(78 / 402)$ in the PMV group $(P=.055)$. Redo was more frequent in the PMV group $(15 \%$ vs $2 \% ; P<.001)$. The observed (unadjusted) event-free survival was similar for both the PMV and OHS groups, and the HR after PMV as compared with after OHS was $1.510(95 \%$ CI, 0.914-2.496; $P=$ .1079; Table 3). However, after adjusting for age, left atrial anteroposterior diameter, and echocardiographic score, the HR was 3.729 (95\% CI, 1.962-7.082; $P<.0011)$, and this trend of a lower event-free survival in the PMV group was confirmed again after adjustment with the propensity score. Both unadjusted and adjusted event-free survival curves are shown in Figure 1 (adjusted Cox model for propensity score). Unadjusted Kaplan-Meier survival curve 


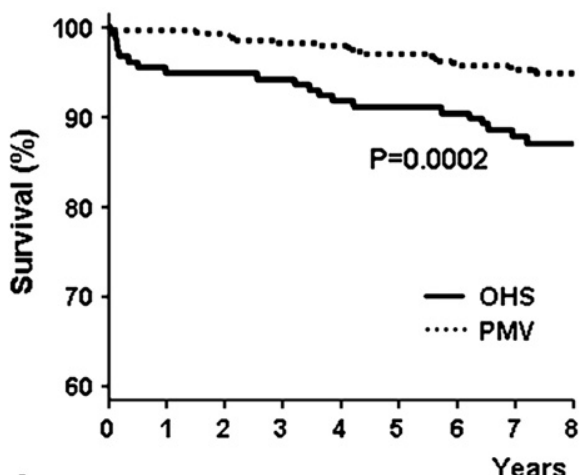

A

Unadjusted

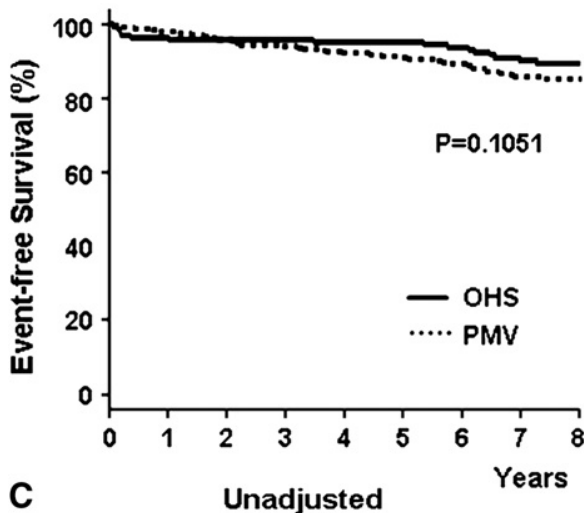

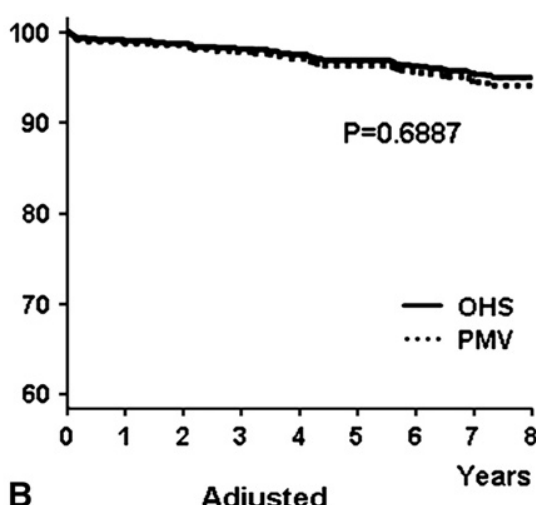

B

Adjusted

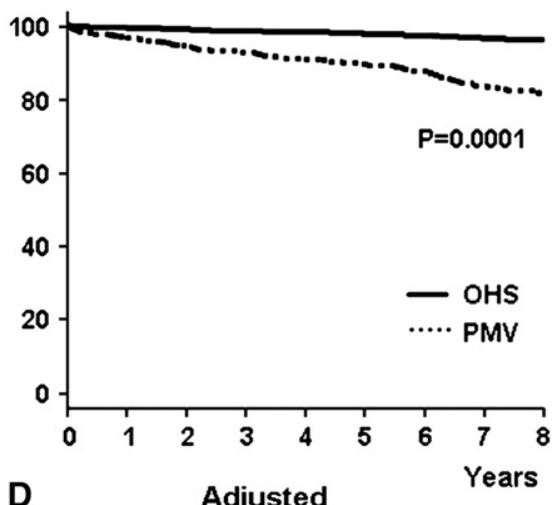

FIGURE 1. Kaplan-Meier analysis. Unadjusted survival (A) and event-free survival (C). Adjusted survival (B) and event-free survival (D). OHS, Open heart surgery; $P M V$, percutaneous mitral valvuloplasty.

analysis showed that the PMV and OHS groups were similar in terms of event-free survival between groups $(P=.1051)$, whereas the survival was higher after OHS than after PMV in the adjusted analysis $(P<.0001)$. The adjusted probability of clinical event-free survival for the OHS groups was $98 \% \pm 1 \%$ at 3 years, $97 \% \pm 1 \%$ at 5 years, $95 \% \pm$

TABLE 3. Hazard ratios for clinical events (cardiovascular death or repeated intervention) for PMV compared with OHS

\begin{tabular}{lccc}
\hline Analytical approach & Hazard ratios & $\mathbf{9 5} \% \mathbf{C I}$ & $\boldsymbol{P}$ value \\
\hline A. The original sample & & & \\
$\quad$ Unadjusted & 1.510 & $0.914-2.496$ & .1079 \\
Adjusted for variables* & 3.729 & $1.962-7.082$ & $<.0001$ \\
Adjusted for propensity & 3.701 & $1.991-6.880$ & $<.0001$ \\
$\quad$ scores & & & \\
B. Stratified & & & \\
analysis based on & & & \\
propensity scores & & & \\
Stratum Q1 & - & - & - \\
Q2 & 1.689 & $0.225-12.661$ & .6098 \\
Q3 & 1.047 & $0.241-4.540$ & .9516 \\
Q4 & 3.444 & $1.310-9.055$ & .0121 \\
Q5 & 2.927 & $1.211-7.075$ & .0171 \\
Summary $\dagger$ & 2.687 & $1.491-4.842$ & .0010 \\
\hline
\end{tabular}

$P M V$, Percutaneous mitral valvuloplasty; $O H S$, open heart surgery; $C I$, confidence intervals. *Adjusting variables: age, left atrial size, and echocardiographic score. $\dagger$ Homogeneous test $P$ value $=.563$.
$1 \%$ at 7 years, and $94 \% \pm 1 \%$ at 9 years; for the PMV group it was $93 \% \pm 1 \%$ at 3 years, $90 \% \pm 1 \%$ at 5 years, $83 \% \pm 1 \%$ at 7 years, and $80 \% \pm 2 \%$ at 9 years.

\section{Effects of Echocardiographic Score and Rhythm}

Event-free survival for both OHS and PMV groups according to the echocardiographic score is illustrated in Figure 2. Patients with echocardiographic scores of 8 or more showed lower event-free survivals after PMV, whereas the echocardiographic score was not associated with eventfree survival after OHS. The adjusted HR for the clinical events after PMV as compared with after OHS in patients with echocardiographic scores of 8 or more was 5.348 (95\% CI, 2.504-11.422; $P<.001$ ), whereas the HR in patients with echocardiographic scores less than 8 was 1.432 (95\% CI, 0.533-5.850; $P=.4767)$.

Before intervention, atrial fibrillation was significantly more prevalent in the OHS group $(84 \%$ vs $36 \% ; P<$ $.001)$. During follow-up, this prevalence decreased from $84 \%$ to $64 \%(102 / 159)$ in the OHS group and increased from $36 \%$ to $53 \%(215 / 402)$ in the PMV group. Conversion of cardiac rhythm from normal sinus rhythm to atrial fibrillation was more frequently observed in the PMV group (17\% [70/402] vs 4\% [6/159]; $P<.001)$. Conversely, spontaneous sinus rhythm conversion from atrial fibrillation 


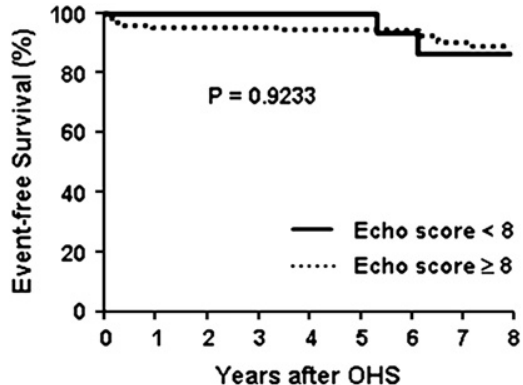

No. at risk

$\begin{array}{llllllllll}\text { Echo score }<8 & 19 & 19 & 18 & 16 & 15 & 15 & 13 & 9 & 5\end{array}$ $\begin{array}{llllllllll}\text { Echo score } \geq 8 & 140 & 127 & 125 & 122 & 118 & 117 & 116 & 89 & 68\end{array}$ A

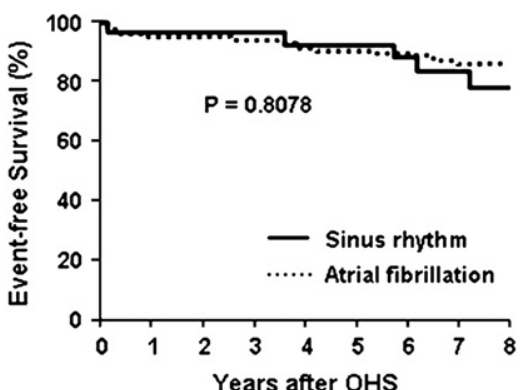

No. at risk

$\begin{array}{llllllllll}\text { Sinus rhythm } & 25 & 24 & 24 & 23 & 22 & 22 & 21 & 15 & 12\end{array}$ $\begin{array}{llllllllll}\text { A.fib } & 134 & 123 & 119 & 115 & 111 & 110 & 108 & 83 & 60\end{array}$

C

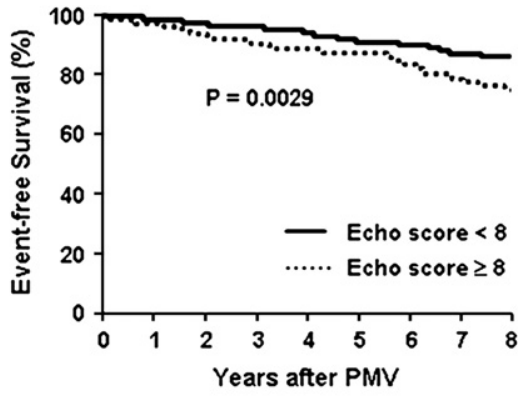

$\begin{array}{lllllllll}243 & 234 & 228 & 218 & 212 & 203 & 195 & 155 & 116\end{array}$ $\begin{array}{lllllllll}159 & 151 & 144 & 134 & 130 & 125 & 116 & 96 & 85\end{array}$

B

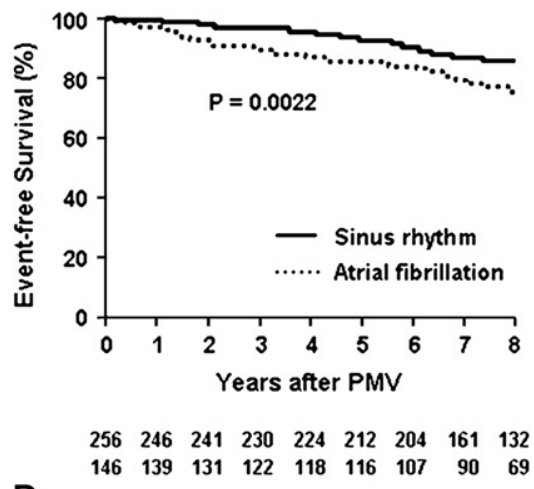

D

FIGURE 2. Kaplan-Meier event-free survival curves according to echocardiographic scores (A and B) and cardiac rhythm (C and D) after open heart surgery $(O H S, \mathrm{~A}$ and $\mathrm{C})$ or percutaneous mitral valvuloplasty $(P M V, \mathrm{~B}$ and $\mathrm{D})$. A-FIB, Atrial fibrillation.

occurred more frequently in the OHS group (24\% [38/159] vs $1 \%$ [2/402]; $P<.001)$. The effect of initial cardiac rhythm on event-free survival in the OHS and PMV groups is shown in Figure 2. Although patients with atrial fibrillation showed lower event-free survivals after PMV, there was no such association between cardiac rhythm and event-free survival in the OHS group. The adjusted HR after PMV as compared with after OHS in patients with normal sinus rhythm was $2.138(95 \% \mathrm{CI}, 0.620-7.368 ; P=$ .2288), whereas the HR in patients with atrial fibrillation was $3.440(95 \%$ CI, $1.805-6.555 ; P=.0002)$. Thus, patients with an echocardiographic score of 8 or more or with atrial fibrillation showed significantly lower eventfree survivals after PMV than after OHS (Figure 3).

\section{DISCUSSION}

The present observational study found that although the adjusted long-term risk of cardiovascular death was similar for both PMV and OHS, the adjusted long-term risk of hard clinical events (including cardiovascular death and redo PMV or repeated OHS) was higher for PMV. Also, both high echocardiographic score $(\geq 8)$ and atrial fibrillation were associated with lower event-free survivals after PMV, but not after OHS, suggesting that these clinical vari- ables should be seriously considered when choosing treatments for patients with MS.

Early randomized, controlled studies showed similar clinical outcomes for both PMV and surgical techniques. ${ }^{17-19}$ This finding may have been largely due to the studies having insufficient statistical power. Such trials involved small numbers of patients ( $<50$ for each intervention) and contained selection biases. Those trials only included young MS patients with a mean age of the mid-to-late twenties. In one study the mean echocardiographic score was 6 using the Wilkins scoring system, ${ }^{19}$ and another trial excluded patients with atrial fibrillation. ${ }^{17,18}$ Such selection criteria are quite different from those used in most current studies in developed countries, which usually include middle-aged MS patients with a mean echocardiographic score of 8 and patients with atrial fibrillation. Given that age and baseline echocardiographic score representing the mitral valve morphologic features are two important factors for both procedural success and long-term event-free survival, ${ }^{6,7,9,11,20,21}$ it is unlikely that data from early clinical trials provide a sound rationale for the current widespread clinical application of PMV in older patients with higher echocardiographic scores or atrial fibrillation. The limitation of previous clinical studies reporting on clinical outcomes after PMV is 

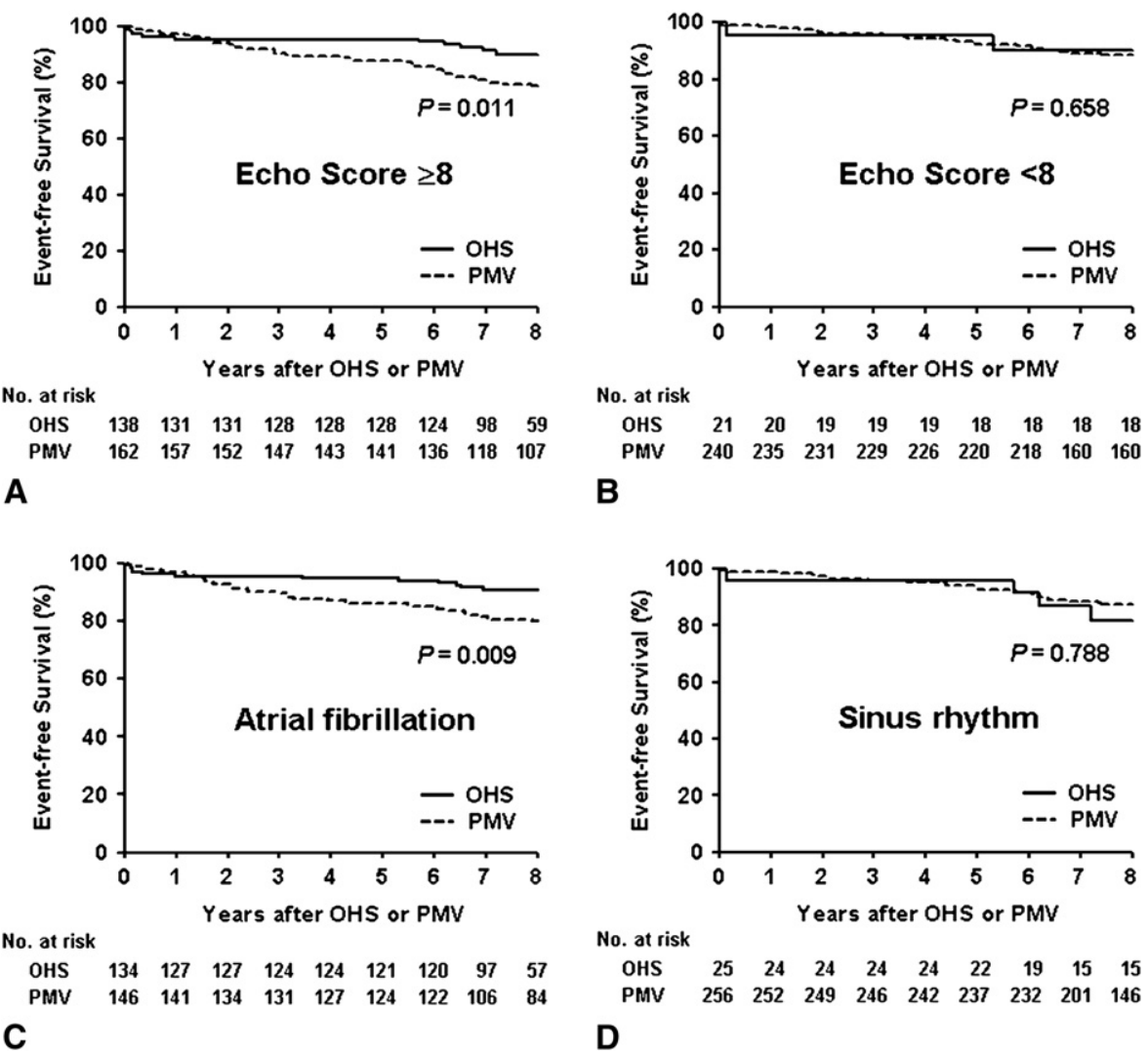

FIGURE 3. Kaplan-Meier event-free survival curves showing different impact of the treatment option (PMV versus OHS) in patients with mitral stenosis having an echocardiographic score of 8 or more or atrial fibrillation. $O H S$, Open heart surgery; $P M V$, percutaneous mitral valvuloplasty.

that the follow-up duration was not long enough to assess the real clinical impact of this intervention, with the duration of most clinical and echocardiographic outcome studies being less than 5 years. Gradual deterioration of functional class and a continued risk of mitral valve surgery after PMV were identified as challenging issues in both the multicenter registry and a large single center report. ${ }^{7,11,22}$ Moreover, sharp deterioration of functional status is reported to begin 5 years after PMV in patients with relatively favorable mitral morphologic features. ${ }^{7}$

OHS including OMC and MVR has a longer history than PMV as a useful treatment option for patients with MS. Along with technical advances and successful clinical introduction of new-generation bileaflet mechanical valves, the superior durability of MVR over OMC has been widely accepted and has led to MVR being recommended as the definitive aggressive treatment option. We found that despite the mean mitral gradient being similar in each group before intervention, it was lower in the OHS group at follow-up $(4.1 \pm 2.1$ vs $6.8 \pm 3.5 \mathrm{~mm} \mathrm{Hg} ; P<.001)$. Moreover, OHS has advantages over PMV in providing the potential for additional surgical techniques to manage tricuspid regurgitation and atrial fibrillation, which frequently accompany MS and are important prognostic factors during long-term follow-up. ${ }^{23-28}$ Contradictory results are available about the impact of atrial fibrillation on short- and long-term outcome after PMV. ${ }^{2,9,29,30}$ All previous studies compared the frequency of development of restenosis or adverse clinical outcomes including redo PMV, MVR, or cardiac death in patients with normal sinus rhythm versus atrial fibrillation; thus, despite higher event rates in patients with atrial fibrillation than in those with sinus rhythm after PMV, ${ }^{2,9,30}$ it has not been known whether OHS is a better strategy than PMV in patients with MS and atrial fibrillation. The present study has confirmed that OHS is a very effective treatment option for MS irrespective of echocardiographic score or cardiac rhythm, and these data suggest that OHS is being underused as the initial intervention in some patients with MS.

The low early morbidity and comparable immediate hemodynamic benefits associated with PMV have led it to become the "gold standard" treatment option in patients with MS, whereas OHS has been reserved for the minority of patients with MS who have atrial thrombi or unfavorable mitral valve morphologic features, including heavy calcification. Thus, the application of OHS for patients with MS has significantly declined. However, the variable nature of baseline clinical characteristics such as age, echocardiographic 
score, and cardiac rhythm can significantly affect prognosis, meaning that simple comparisons of event-free survivals or mortality between PMV and OHS groups is not sufficient to draw firm conclusions given selection bias. Selection bias was minimized in the present study by adjusting for differences among patients in terms of demographic characteristics, coexisting conditions, and echocardiographic features including mitral valve morphologic features and hemodynamic state. Nevertheless, there remains the possibility that observational studies may fail to identify all confounders, and it is also true that propensity analyses cannot account for selection bias related to unmeasured characteristics.

The current study was not a randomized, controlled trial and suffers from significant difference of baseline characteristics between PMV and OHS groups. Despite unfavorable conditions in the OHS group, including significantly higher mean age, echocardiographic score, and higher prevalence of atrial fibrillation, sophisticated statistical data transformation demonstrated the superiority of OHS. We believe this finding supports the necessity of a randomized, controlled trial with long-term follow-up. In addition, the choice of treatment was left to the physician in this study, and one of the treatment options may have been contraindicated in some patients. Moreover, there are often many considerations when choosing the appropriate intervention for patients with MS. PMV is far less invasive than OHS and has a lower early morbidity, resulting in many patients possibly preferring this option. Further cost-benefit analysis comparing PMV and OHS is required, particularly taking into consideration the life expectancy and the relative merits of short- and long-term risks. Lack of data regarding other complications, including nonfatal embolic episodes, which could affect the quality of life, is another limitation of this study. Less than $20 \%$ of patients with atrial fibrillation underwent an antiarrhythmic procedure during OHS in this study, inasmuch as the maze procedure was not fully established in our institution during the study period and there was a major concern about the efficacy of the maze procedure in patients with rheumatic MS and a large left atrium. Inasmuch as we have confirmed the superiority of OHS, even without the additive antiarrhythmic procedure, this limitation does not mitigate the main finding of our study.

In conclusion, as better long-term outcome is anticipated in patients with echocardiographic scores of 8 or more or with atrial fibrillation after OHS, careful consideration is warranted in choosing the appropriate treatment option in these selected patients.

\section{References}

1. Inoue K, Owaki T, Nakamura F, Kitamura F, Miyamoto N. Clinical application of transvenous mitral commissurotomy by a new balloon catheter. J Thorac Cardiovasc Surg. 1984;87:394-402.

2. Palacios IF, Block PC, Wilkins GT, Weyman AE. Follow-up of patients undergoing percutaneous mitral balloon valvotomy. Analysis of factors determining restenosis. Circulation. 1989;79:573-9.
3. Nobuyoshi M, Hamasaki N, Kimura T, Nosaka H, Yokoi H, Yasumoto H, et al. Indications, complications, and short-term clinical outcome of percutaneous transvenous mitral commissurotomy. Circulation. 1989;80:782-92.

4. Vahanian A, Michel PL, Cormier B, Vitoux B, Michel X, Slama M, et al. Results of percutaneous mitral commissurotomy in 200 patients. Am J Cardiol. 1989;63: 847-52.

5. Multicenter experience with balloon mitral commissurotomy. NHLBI Balloon Valvuloplasty Registry Report on immediate and 30-day follow-up results. The National Heart, Lung, and Blood Institute Balloon Valvuloplasty Registry Participants. Circulation. 1992;85:448-61.

6. Cohen DJ, Kuntz RE, Gordon SPF, Piana RN, Safian RD, McKay RG, et al. Predictors of long-term outcome after percutaneous balloon mitral valvuloplasty. N Engl J Med. 1992;327:1329-35.

7. Meneveau N, Schiele F, Seronde MF, Breton V, Gupta S, Bernard Y, et al. Predictors of event-free survival after percutaneous mitral commissurotomy. Heart. 1998;80:359-64

8. Hernandez R, Banuelos C, Alfonso F, Goicolea J, Fernandez-Ortiz A, Escaned J, et al. Long-term clinical and echocardiographic follow-up after percutaneous mitral valvuloplasty with the Inoue balloon. Circulation. 1999;99: 1580-6.

9. Iung B, Garbarz E, Michaud P, Helou S, Farah B, Berdah P, et al. Late results of percutaneous mitral commissurotomy in a series of 1024 patients. Analysis of late clinical deterioration: frequency, anatomic findings, and predictive factors. $\mathrm{Circu}$ lation. 1999;99:3272-8.

10. Kang DH, Park SW, Song JK, Kim HS, Hong MK, Kim JJ, et al. Long-term clinical and echocardiographic outcome of percutaneous mitral valvuloplasty. Randomized comparison of Inoue and double-balloon techniques. J Am Coll Cardiol. 2000;35:169-75.

11. Palacios IF, Sanchez PL, Harrel LC, Weyman AE, Block PC. Which patients benefit from percutaneous mitral balloon valvuloplasty? Prevalvuloplasty and postvalvuloplasty variables that predict long-term outcome. Circulation. 2002;105: 1465-71.

12. Cohen JM, Glower DD, Harrison JK, Bashore TM, White WD, Smith R, et al. Comparison of balloon valvuloplasty with operative treatment for mitral stenosis. Ann Thorac Surg. 1993;56:1254-62.

13. Cotrufo M, Renzulli A, Vitale N, Nappi G, De Feo M, Ismeno G, et al. Long term follow-up open commissurotomy versus bileaflet valve replacement for rheumatic mitral stenosis. Eur J Cardiothorac Surg. 1997;12:335-40.

14. Glower DD, Landolfo KP, Davis RD, Cen YY, Harrison JK, Bashore TM, et al. Comparison of open mitral commissurotomy with mitral valve replacement with or without chordal preservation in patients with mitral stenosis. Circulation. 1998; 98(Suppl II):II120-3.

15. Wilkins GT, Weyman AE, Abascal VM, Block PC, Palacios IF. Percutaneous balloon dilatation of the mitral valve: an analysis of echocardiographic variables related to outcome and the mechanism of dilatation. Br Heart J. 1988; 60:299-308.

16. Cain KC, Lange NT. Approximate case influence for the proportional hazards regression model with censored data. Biometrics. 1984;40:493-9.

17. Turi ZG, Reyes VP, Raju S, Raju AR, Kumar DN, Rajagopal P, et al. Percutaneous balloon versus surgical closed commissurotomy for mitral stenosis. A prospective randomized trial. Circulation. 1991;83:1179-85.

18. Reyes VP, Raju BS, Wynne J, Stephenson LW, Raju R, Fromm BS, et al. Percutaneous balloon valvuloplasty compared with open surgical commissurotomy for mitral stenosis. N Engl J Med. 1994;331:961-7.

19. Farhat MB, Ayari M, Maatouk F, Betbout F, Gamra H, Jarrar M, et al. Percutaneous balloon versus surgical closed and open mitral commissurotomy. Seven-year follow-up results of a randomized trial. Circulation. 1998;97: 245-50.

20. Pavlides GS, Nahhas GT, London J, Gangadharan C, Troszak E, Barth-Jones D, et al. Predictors of long-term event-free survival after percutaneous balloon mitral valvuloplasty. Am J Cardiol. 1997;79:1370-4.

21. Fawzy ME, Hegazy H, Shoukri M, Shaer FE, ElDali A, Al-Amri M. Long-term clinical and echocardiographic results after successful mitral balloon valvotomy and predictors of long-term outcome. Eur Heart J. 2005;26:1647-52.

22. Dean LS, Mickel M, Bonan R, Holmes DR, O'Neill WW, Palacios IF, et al. Fouryear follow-up of patients undergoing percutaneous balloon mitral commissurotomy. A report from the National Heart, Lung, and Blood Institute Balloon Valvuloplasty Registry. J Am Coll Cardiol. 1996;28:1452-7.

23. King RM, Schaff HV, Danielson GK, Gersh BJ, Orszulak TA, Piehler JM, et al Surgery for tricuspid regurgitation late after mitral valve replacement. Circulation. 1984;70(Suppl I):193-7. 
24. Matsuyama K, Matsumoto M, Sugita T, Nishizawa J, Tokuda Y, Matsuo T. Predictors of residual tricuspid regurgitation after mitral valve surgery. Ann Thorac Surg. 2003;75:1826-8.

25. McCarthy PM, Bhudia SK, Rajeswaran J, Hoercher KJ, Lytle BW, Cosgrove DM, et al. Tricuspid valve repair: durability and risk factors for failure. J Thorac Cardiovasc Surg. 2004;127:674-85.

26. Kim HK, Kim YJ, Kim KI, Kim KH, Kim KB, Ahn H, et al. Impact of the Maze operation combined with left-sided valve surgery on the change in tricuspid regurgitation over time. Circulation. 2005;112(Suppl I):I14-9.

27. Stulak JM, Schaff HV, Dearani JA, Orszulak TA, Daly RC, Sundt TM 3rd. Restoration of sinus rhythm by the Maze procedure halts progression of tricuspid regurgitation after mitral surgery. Ann Thorac Surg. 2008;86: 40-4.

28. Je HG, Song H, Jung SH, Choo SJ, Song JM, Kang DH, et al. Impact of the Maze operation on the progression of mild functional tricuspid regurgitation. $J$ Thorac Cardiovasc Surg. 2008;136:1187-92.

29. Tarka EA, Blitz LR, Herrmann HC. Hemodynamic effects and long-term outcome of percutaneous balloon valvuloplasty in patients with mitral stenosis and atrial fibrillation. Clin Cardiol. 2000;23:673-7.

30. Langerveld J, Hemel NMV, Ernst SMPG, Plokker HWT, Kelder IC, Jaarsma W. The predictive value of chronic atrial fibrillation for the short- and long-term outcome after percutaneous mitral balloon valvotomy. J Heart Valve Dis. 2001;10:530-8.

Access to The Journal of Thoracic and Cardiovascular Surgery Online is reserved for print subscribers!

Full-text access to The Journal of Thoracic and Cardiovascular Surgery Online is available for all print subscribers. To activate your individual online subscription, please visit The Journal of Thoracic and Cardiovascular Surgery Online, point your browser to http://www.mosby.com/jtcvs, follow the prompts to activate your online access, and follow the instructions. To activate your account, you will need your subscriber account number, which you can find on your mailing label (note: the number of digits in your subscriber account number varies from 6 to 10). See the example below in which the subscriber account number has been circled:

\section{Sample mailing label}

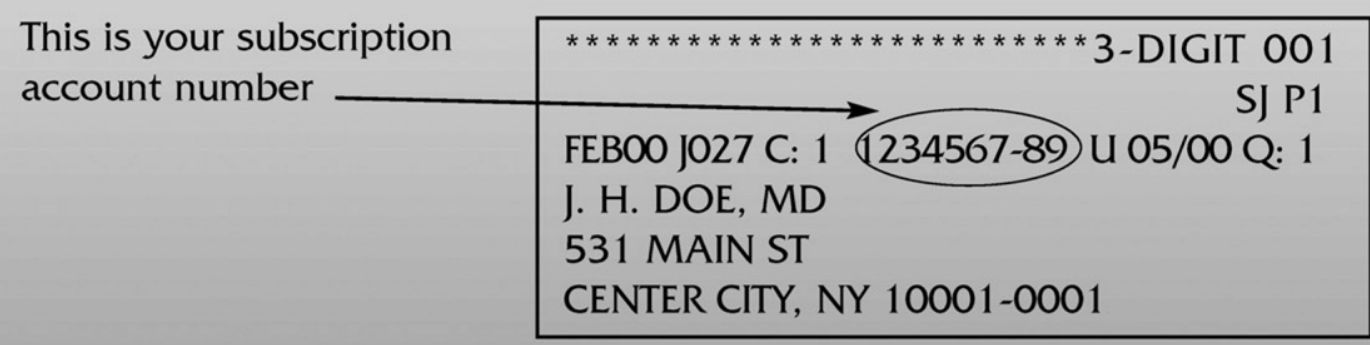

Personal subscriptions to The Journal of Thoracic and Cardiovascular Surgery Online are for individual use only and may not be transferred. Use of The Journal of Thoracic and Cardiovascular Surgery Online is subject to agreement to the terms and conditions as indicated online. 